\title{
A silent cry for leadership: Organizing for leading (in) clusters
}

\author{
Jörg Sydow ${ }^{\mathrm{a}}$, Frank Lerch ${ }^{\mathrm{a}}$, Chris Huxham ${ }^{\mathrm{b}}$, Paul Hibbert ${ }^{\mathrm{b}}$ \\ ${ }^{a}$ Department of Management, Freie Universität Berlin, Boltzmannstr. 20, D-14195 Berlin, Germany \\ ${ }^{b}$ AIM Research / University of Strathclyde Business School, Cathedral Street, Glasgow, United Kingdom \\ Corresponding author: \\ Jörg Sydow \\ Freie Universität Berlin, \\ Department of Management \\ Boltzmannstr. 20 \\ 14195 Berlin-Dahlem (Germany) \\ Tel: $+49(0) 30-83853783$, \\ Fax: +49 (0) 30-838 56808 \\ Email: joerg.sydow@fu-berlin.de
}

\begin{abstract}
Leadership research so far has neglected regional clusters as a particular context, while research on networks and clusters has hardly studied leadership issues. This paper fills this dual gap in the abundant research on leadership on the one hand and on networks/clusters on the other by investigating leadership in four prominent photonics clusters in England, Scotland, Germany and the United States. Apart from giving an insight into the variety and patterns of leadership practices observed in these clusters, the paper addresses the dilemma that regional innovation systems such as clusters usually have a critical need of some kind of leadership, but that neither individual nor organizational actors wish to be led. This dilemma or paradox can only be 'managed' by organizing for leading (in) clusters in a way that takes into account the tensions and contradictions surrounding leadership of and in clusters. The argument is based upon the idea of leading as reflexive structuration that has far-reaching implications for leadership research not only in this and other macro contexts but also in more traditional contexts.
\end{abstract}

Keywords: cluster; leadership; network; organizing; structuration; relations

Acknowledgements: We thank participants at the AIM/CORGies international workshop "Making Connections: Relational Analysis, Boundary Concepts and the Future of Organization Studies", Cardiff Business School, April 2-3, 2007, at the AIM workshop "Clusters and Networks" at Strathclyde University Business School, April 10, 2007, at the BAM annual conference in Warwick, September 11-13, 2007, and at the ANZAM annual conference in Melbourne, December 2-4, 2009, for comments on developing conceptualizations and earlier versions of this manuscript. In particular, we thank Hugh Willmott as well as several anonymous reviewers, including two for LQ, for their insightful comments on earlier versions of this paper. We would also like to acknowledge the support of the ESRC/EPSRC Advanced Institute of Management (AIM) Research, grant number RES-331-250016.

Accepted for publication in: Leadership Quarterly 22 (2011) 


\section{Introduction: The need for research on leadership in clusters}

Fred Fiedler (1967) was among the first to propose switching the focus of leadership research from the traits or behaviors of leaders to contingencies of the situation in order to better understand the efficacy of a certain form or style of leadership. Since then, the context of leadership has almost always been taken into consideration; even if some 'new' theories of leadership have turned their attention back to the (charismatic, transformational or visionary) leader and his or her cognitive capacity, social intelligence, or behavioral complexity (cf. Boal \& Hooijberg, 2001, for a recent review). Nonetheless, leadership research tends to concentrate on the most immediate context of those who lead and those who follow. That is, this research largely centers on leadership in dyads, groups or organizations, neglecting socially more distant, ambiguous and complex contexts including national cultures, ethnic communities and the now omnipresent inter-organizational arrangements such as strategic alliances, supply networks, public-private partnerships, or regional clusters and innovation systems. Hence, it comes as no surprise that a growing number of leadership scholars call for approaches to leadership research that take wider contexts into account (e.g. Osborn, Hunt \& Jauch, 2002; Osborn \& Marion, 2009). Following this call, however, has far reaching implications for theorizing leadership.

Regional clusters - i.e. geographic concentrations of quite a large number of interacting, more or less networked organizations in an industry and related fields (Porter, 1998) - offer an opportunity to study leadership in a rich, macro context which has two features that render it of particular interest. First, this organizational form of economic activity is definitively on the rise and thus it is timely to study it. In their Cluster Initiative Greenbook, Sölvell, Linqvist and Ketels (2003) discuss 238 cluster initiatives but suggest that they represent only a tiny fraction of the picture, especially if emergent clusters are considered as well as those 
that have been formally developed. Since the publication of the Greenbook the spread of this particular form of organizing seems to have accelerated (Ketels, Linqvist \& Sölvell, 2006).

Second, regional clusters are extremely ambiguous, diverse, complex and dynamic. They are not only made up of numerous organizations from different "societal spheres" (Giddens, 1984), such as the economic and scientific, but often exhibit unclear boundaries (Martin \& Sunley, 2003: 11). To make the issue even more organizationally tangled, clusters or at least "networks in clusters" (Sydow \& Lerch, 2007), that result from inter-organizational interaction, may be strategically led by a "hub firm" (Jarillo, 1988) or "network orchestrator" (Dhanaraj \& Parke, 2006). Sometimes, a "network administrative organization" (Human \& Provan, 2000) may have been created specifically to support cluster leadership. Interestingly, despite their network- or rather cluster-oriented role, these tend to be hierarchical organizations but support network/cluster leadership that typically cannot rely on hierarchy. In addition, some distinct individuals may act as "cluster leaders" (Casson, 2003) (perhaps more appropriately termed as "cluster entrepreneurs" (Feldman \& Francis, 2006), "cluster facilitators" (Ketels, 2003), or "district champions" (Zucchella, 2006) acting on behalf of either a hub firm or network administrative organization adding another (individual) level of leadership to be considered. Thus regional clusters appear to be not only particularly complex, ambiguous, diverse, and dynamic contexts for leadership but also to require, more than other contexts, a multi-level approach (e.g. Hunt \& Ropo, 1995; Yammarino \& Dansereau, 2008). This type of complexity may be indicative of future leadership contexts.

Despite the prevalence of clusters, the obvious but very diverse role of leadership in these social systems, and their multi-level nature from a leadership perspective, leading (in) clusters has hardly been studied. As our review of the literature will show, leadership in networks has so far been only of peripheral interest to management research (see Feyerherm, 
1994; Beyer \& Browning 1999; Fleming \& Waguespack, 2007, for notable exceptions). When the term 'leadership' is in turn used by cluster researchers, even the very basics of leadership research are not taken into consideration (cf. Bass, 1990; Yukl, 2006). For instance, leadership is not defined and the style or form of leadership is not tackled. Even more importantly, individual and organizational leadership are not distinguished (e.g. Casson, 2003; Zucchella, 2006). Therefore, addressing both scholars of leadership and of clusters, in this paper we start by asking the following questions: who leads (in) clusters?, how and under which circumstances?, and what are the particular challenges of this context? However, we go beyond these very basic questions when we address - as is increasingly common in organization and network research - paradoxes, dialectics, and tensions in management practice (e.g. Huxham \& Beech, 2003; Sundaramurthy \& Lewis, 2003; De Rond \& Bouchikhi, 2004).

In order to do so, we first discuss the two concepts central to our study: cluster and leadership. This conceptual part of the paper draws upon traditional cluster and leadership research but, in addition, takes a theoretical perspective that emphasizes "structuration" (Giddens, 1984) - i.e. the deliberate and emergent structuring of social systems such as formal organizations and regional clusters through structure-guided and structure reproducing practices. This part, which we conceive as an important theoretical contribution to more context-sensitive leadership research, is followed by the presentation of the methodology for our empirical study which includes a short description of the four photonics or optics clusters in England, Scotland, Germany and the United States in which it is situated. The fourth and fifth sections of the article cover our structuration-influenced empirical analysis. In the fourth we derive a typology of cluster leadership through a comparative analysis of the four clusters. Building on this, the fifth portrays a cumulative analysis, through which we develop a characterization of leadership of and in clusters and, thereby, clarify who leads (in) clusters, 
how and under what circumstances. These characteristics are important, both for illuminating how leadership can be achieved in these complex, diverse, ambiguous and dynamic contexts, but they also highlight a paradox which we discuss in the penultimate section. The paper concludes with limitations of the present study and implications for future leadership and cluster research.

\section{Leadership in and of clusters: A structuration perspective}

In this section we aim to blend extant research that defines relevant features of clusters, with those aspects of leadership research that are particularly germane to those features. Onto that synthesis, we overlay relevant aspects of structuration theory.

\subsection{Clusters and Leadership defined}

The cluster concept is based upon early work on industrial complexes by Alfred Marshall (1890) and later studies of industrial districts by Brusco (1982) and others, promulgated by Piore and Sabel (1984) and soon after developed in industrial and regional economics (Porter, 1990; Krugman,1991) and other regional sciences (e.g. Asheim, Cooke \& Martin, 2006). According to Porter (1998: 197), "clusters are geographic concentrations of interconnected companies, specialized suppliers, service providers, firms in related industries, and associated industries in a particular field that compete but also co-operate." This prevalent conceptualization has received widespread criticism, particularly in relation to the inadequate specification of central concepts like regional proximity or collaborative and competitive linkages (Martin \& Sunley, 2003). However as Jacobs and de Man (1996) suggest, this very ambiguity offers conceptual flexibility in the implementation of cluster policies, which might 
explain their widespread application (Sölvell et al., 2003). Despite this ambiguity around the notion of clusters, there seems to be a generally held view that 'soft factors' like a trusting atmosphere, fairly free information flow, and a dominantly collaborative milieu - all of which have implications for leadership - seem to be important in the cluster context (e.g. Maillat, 1991; Rosenfeld, 1996).

While traditional leadership research typically takes a dyadic leader-follower approach (e.g. Bryman, 1996) which is not generally applicable in the type of context just described, there are perspectives on leadership that are of more potential relevance. For example, the importance of social networks for leadership - including even the role of cohesive boundaries and isolated brokerage (Fleming \& Waguespack, 2007) - has been acknowledged by some management researchers (e.g. Balkundi \& Kilduff, 2005; several chapters in Graen \& Graen, 2006). There is also a small body of work addressing leadership in alliances and networks which, like clusters, are inter-organizational and lack hierarchy. Orton and Weick (1990), for example, posit subtle, indirect forms of leadership as typical for what they term "loosely coupled systems", and Feyerherm (1994) explores how leadership behavior influences the convergence of cognitive frames used by participants in inter-organizational problem solving. Beyer and Browning (1999) studied charismatic leadership in an R\&D consortium, conceiving of it not so much as an attribute of a charismatic, transformational or visionary leader, but rather as "cultural leadership" that influences how the "followers collectively think and act" based upon its embeddedness in the "cooperative linking structures" of the consortium. More generally, Huxham and Vangen $(2000,2005)$ focus on the "doing of leadership" in collaborative situations, emphasizing both the role played by structures and processes and the contrasting facilitative and directive roles that leaders need to play. Denis, Lamothe and Langley (2001) point to the need for "collective leadership" that, however, due to the tendency of respective leadership constellations to disconnect, is rather fragile. In 
contrast to these approaches, Bryson and Crosby (2006) study the particular conditions under which leadership occurs in collaborative settings, emphasizing the shared-power setting in the case they studied. Even more recently, Barden and Mitchell (2007) examine how leaders' prior exchange experiences in networks influence the likelihood of subsequent interorganizational exchange. Finally, Osborn and Marion (2009) investigate international innovation alliances by adopting a "three party view of alliance success" and distinguishing the "dynamic" context of the leaders of the partner firms and the "edge-of-chaos" context the leader of the alliance has to act in.

While all of these studies have relevance, none explicitly considers network leadership in the context of regional clusters. Leadership in this context is conceived here as individual and/or organizational action that is based upon a set of social relationships and "makes things happen" (Huxham \& Vangen, 2000), often through influencing the actions of others (see also Bass, 1990) via the production and reproduction of structures. Speaking of an organization, such as a hub firm or a cluster organization, "leading" others is only short-hand for a particular organizational member - as a "boundary spanner" (Adams, 1980) - or an organized collectivity of individuals from a particular organization making things happen on behalf of their organization or the cluster. For reasons of brevity we do refer to organizations "acting" or "leading", but the statements should be interpreted in the manner described above.

\subsection{Leading (in) Clusters as Reflexive Structuration}

From a perspective that seeks to apply structurational concepts rather directly in empirical research (Sydow \& Windeler, 1998), clusters are conceived as social systems that are characterized by time-space relations with structural properties that are at the same time an outcome of action and medium of action. We conceive of structural properties as relating to 
both 'soft' features (such as trust or information flow) as well as 'hard' features (such as committee structures) of clusters. The perspective conceives of 'agents' - people or, in the case of clusters, organizations - as referring to structural properties more or less consciously in their practices, not least in their leadership practices (Giddens, 1979, 1984; see also Urry, 1991). With regard to acknowledging the relevance of relations, such a structuration perspective is similar to the emerging relational approach to leadership (see Uhl-Bien, 2006, for an excellent summary).

From a structuration perspective, whatever the concrete objectives of the individuals or the organization in a particular context, leadership in general aims at creating, producing, reproducing or transforming - via direct and indirect actions - a social order that is always precarious and requires leadership as one "organizing activity" (Hosking, 1988). As a component of cluster management practices, leadership is conceived here as reflexive structuration. By this notion we wish to highlight the practices of individual or organizational actors that make things happen by influencing others based upon a "reflexive monitoring" (Giddens, 1984) of their action, its consequences and contextual conditions, not least with regard to the set of relationships it is embedded in. This structurationist understanding of leadership allows not only for purposeful actions but also for emergent properties of social order. It takes not only the immediate but also the wider historical, political and cultural context of social practices into account. Moreover, this context does not remain "outside" leadership action but is enacted and reproduced or transformed by respective leadership practices (see also Osborn et al., 2002; Drath, McCauley, Palus, Van Velsor, O’Connor \& McGuire, 2008). Importantly, in the case of cluster leadership these practices are not restricted to activities located within an organization but cut across organizational and even network boundaries. 
With regard to who leads whom in a cluster, the subject and object of agency may also vary, with leadership possibly being attributed to: individuals leading other individuals, organizations, inter-organizational networks within the cluster, or the entire cluster; organizations leading individuals, other organizations, networks or the cluster; and perhaps even inter-organizational networks or clusters leading individuals and organizations. In all these latter cases, of course, human agents act on behalf of systems in order to 'make things happen' through the actions of others. Therefore, leading (in) clusters is likely to focus on activities like motivating, involving, empowering, supporting, sense-making, mobilizing, controlling, manipulating, legitimizing and representing (Huxham \& Vangen, 2005); activities that, at least on first sight, are not very different from leadership executed in organizational contexts.

In line with this reasoning, cluster leadership translates into an individual or organization leading a cluster. It is mainly based upon cluster rules and resources, cuts across organizational and sometimes even network boundaries, and often aims at mobilizing large numbers of individuals and/or organizations that - together with their relationships - make up the regional cluster. Cluster leadership is most adequately described as relational leadership. ${ }^{1}$ This is mainly because of the networked character of (real) clusters. Cluster leadership implies that the cluster - or at least most of its members - are the 'object' of leadership. However, for a complete picture, leading in clusters is also important; in this case, which is only touched upon in this article, only a subgroup of cluster organizations is targeted in. Leading in a cluster may take a wide variety of forms. For instance, it may aim at making things happen in a dyadic relationship or a more complex network of relationships that, nevertheless, is not identical with the cluster. 
To both ends leaders, embedded in this cluster or these relationships, refer to its/their structural properties in their leadership practices and either reproduce or transform them when influencing the actions of others. In both cases, the reflexive structuration perspective on leading (in) clusters implies that while practices of leading a cluster as a whole may influence the practices individual or organizational actors apply in leading in clusters, these latter practices of leading in clusters in turn mediate the usage of cluster leadership.

\subsection{Rules and Resources in the Structuration of Leadership Practices}

In sharp contrast to leadership inside organizations, relational leadership in or of clusters is of a genuinely non-hierarchical nature, often based upon negotiations rather than "commands and controls", and always crossing organizational boundaries. Obviously, this is not to say that leadership inside organizations is at all times based on command and control but it is always carried out in the shadow of the possibility of hierarchical fiat; this possibility does not exist in clusters. Despite this important difference, relational leadership is nevertheless “mediated by relations of power" (Knights \& Willmott, 1992: 767).

Leaders are those who, more than others, are thought of as influencing the social activities and relationships towards the production, reproduction or transformation of a social order (Bass, 1990; Drath et al., 2008). From a structuration perspective, leaders as (powerful) "knowledgeable agents" (Giddens, 1984) are able to lead because they have not only the capability for reflexive monitoring but also easier access to and/or a better command of organizational or, in this case, 'cluster resources' such as public funding (an allocative resource) or a mandate to act as a cluster leader (an authoritative resource). In consequence, leaders enjoy a higher status and/or a more central position relative to others "in terms of their contributions to influence" (Hosking, 1988: 152). A structuration perspective is able to 
consider how these power differentials interplay with individual and organizational actions, and the structural properties of social contexts during the process that can be understood as leading (in) clusters.

Leadership, like any action, necessarily relies on structures (including relationships) that are produced and reproduced - and eventually transformed - by the very action that 'makes things happen'. In contrast to much traditional leadership research, from a structuration perspective leadership appears as a social practice that relies on individual or collective action but is conceived as being enabled as well as constrained by structures. Structures, from this perspective, are not only comprised of resources of domination, including, for example, a financial budget or a planning device that allows agents - as leaders - to intervene powerfully into ongoing practices. Rather, structures also comprise rules of signification and legitimation (Giddens, 1984). An example of a rule of signification in the cluster context would be shared interpretations among most cluster members about the cluster purpose, while an illustration of a rule of legitimation would be more or less shared norms about acceptable behavior in the cluster. Both kinds of rules, which only exist in their implicit manifestation "in social practices or as memory traces orienting the conduct of knowledgeable human agents" (Giddens, 1984: 17), enable and constrain participants' - a not least leaders' - behavior.

The enactment of cluster rules and resources by powerful knowledgeable agents, in specific locales through leadership practices is clearly an important element of cluster leadership. However, the structural properties of other, more 'distant' or 'surrounding' contexts such as those of the national or regional innovation system (e.g. Lundvall 1992; Nelson 1993; Cooke, Braczyk \& Heidenreich, 2004) also influence the possibilities and limits of leadership. For instance, alternative interpretations offered by a cluster leader may be embedded and reembedded in the wider discourse on high-tech clusters in a national or even transnational 
context. From the structurationist perspective, such rules and resources should, of course, not only be conceived as an important condition, but also as an outcome and a medium of cluster leadership.

As will be indicated in the following section, the structurational framing of leadership in clusters formed a backdrop to our empirical analysis. While this rather direct use of such concepts in empirical studies may be debateable, we are not alone in using structuration theory in this way (e.g. Orlikowski, 1992; Sydow \& Windeler, 1998; Berends, Boersma \& Weggeman, 2003). Moreover, this approach does not exclude the development of empirically richer theories that are informed by structuration theory as an "intermediate theory" (Bryant \& Jary, 2001). In the following section, we discuss our methodological approach in detail.

\section{Studying leading (in) clusters: Methodology}

As indicated previously, the empirical study was carried out in four Photonics clusters. Photonics is a science-based industry, that turns knowledge from physics, chemistry, material sciences, biology, medicine and/or engineering into products as diverse as lasers, lighting systems, and measuring and control devices (which in turn can be found in applications like cameras, lamps, remote controls, laser welding machinery, or internet backbone infrastructure to name just a few). It is, technologically, extremely complex and dynamic, relying on intensive inter-organizational interaction between research organizations on the one hand and firms that can develop and market the technology on the other. Moreover - and this represents another major reason why it has been selected for study - this industry clusters in certain regions of the world (Hendry et al., 2000; Sydow \& Lerch, 2007; Feldman \& Lendel, 2009). With a cluster size between 60 and 260 firms plus other types of organizations, the 
importance of industry-science collaborations as well as the presence of organizations belonging to other and related industries (automotive, electronics, defense, etc.) applying optics and photonics, these clusters surely provide the complex, diverse, dynamic, and ambiguous contexts we were looking for.

We studied the development of four photonics clusters at different points in time over a period of seven years (2000-2006); all clusters studied are of major economic importance, not only for the regions they are located in, but also for the global photonics industry. Photonics is an interesting high-tech field that has recently gained a lot of political and economic attention; as an enabling technology (NRC, 1998) it is "the technology of the $21^{\text {st }}$ century" (Rickman, 2000; Niehoff \& Pearshall, 2005) as industry insiders comment. Among other issues, we were interested in the role of leadership practices in developing these four clusters. Our study contributes to the qualitative line of inquiry that has entered leadership research yet still seems to be a relatively underutilized methodology. Like structuration theory, such a qualitative approach has greater sensitivity to the multi-contextual nature of leadership, is able to come up with unexpected results, and has a superior ability to capture the richness of the contexts as well as actors' individual views of, and influence on, process (e.g. Bryman, Bresnen, Beardsworth \& Keil, 1988; Hunt \& Ropo, 1995; Conger, 1998; Sjöstrand, Sandberg \& Tyrstrup, 2001; and Bryman, 2004, for a recent review).

Our research methodology adopts a multiple case study design with the four regional clusters as our units of analysis providing us with a fair chance to check for internal and external validity (Eisenhardt, 1989; Yin, 2009). Nevertheless, following Eisenhardt (1989), the purpose of our emergent multiple case study research is not theory-testing but rather theorydevelopment or, in this case more precisely, theory-differentiation and -specification. Structuration theory - as indicated above - is directly or indirectly used as "sensitizing 
device" (Giddens, 1984) for framing, structuring and interpreting the data. This process of theory-guided induction has similarities to other interpretive approaches such as researchoriented action research (Eden \& Huxham, 2006) and organizational ethnography (Heracleous, 2000; Weeks, 2000; Humphreys, Brown \& Hatch, 2003). Nevertheless our approach deviates from these by using the framework of a formal social theory that provides highly sophisticated but extremely abstract concepts that need study object-related specification. In this case, we started by studying leadership practices in and of clusters as outlined above, and how they related to "cluster rules", "cluster resources", and "regionalized locales". We went beyond this by developing a classification or typology of leading (in) clusters and an integrative treatment of the paradoxes and tensions implicit in these systems.

The four clusters were selected in an emergent way as the study was not originally conceptualized as comparative research. While two of the authors were already involved in an in-depth case study in Berlin-Brandenburg (since 2000), the possibility of studying leadership arose when making a first, rather rough comparison of this evolving photonics cluster with the world's best-known photonics cluster in Southern Arizona (in 2004). In 2005 the opportunity came up to extend the comparison to two British clusters in Scotland and the West Midlands. At this point in time, the idea grew that the study should, in particular, focus on leading (in) clusters, because it is an uncharted terrain in leadership research as much as in cluster research. Whilst this ex post shift of study focus was no problem in the BerlinBrandenburg case (because of the extensive involvement of two of the authors in the clusterbuilding process as researchers and, sometimes, consultants, over a rather long period of time), it caused some difficulties with regard to the Arizona case. These problems, however, were overcome through a second round of interviews focused more specifically on leadership in Arizona in late 2006 and early 2007. 
Altogether 39 interviews were conducted with the directors or CEOs of very different types of organizations in each of the clusters (see Table 1). Since most of these organizations (companies, research organizations, consultancies) were fairly small, the data collected from one informant are assumed to represent the perspective of the respective organization. In the larger organizations we interviewed those who spanned the boundary between the organization and the cluster. In most cases our interviewees were either at one point in time or, more often, continuously actively involved in the development of the cluster. This was our main criterion for selection. In addition we interviewed representatives of the cluster organization in each of the clusters - in two cases (Southern Arizona and Scotland), these were the heads of the respective optical industry associations; in the other two cases they were the heads of the network administrative organization (NAO). Starting from these, the interviewees were selected using a snowball method. However, in each of the four cases we made sure that not only people from the centre but also from the periphery of the cluster were interviewed in order to obtain a more valid picture of who leads whom. The interviews were semi-structured, took on average 90 minutes, and focused not only on leading (in) clusters but also on topics such as the origin and development of the cluster, the intensity of interaction in and the formal governance as well as the boundaries of the cluster. Interviewees were encouraged to give detailed examples, particularly with respect to leadership issues. The broadness of the interview enabled us to analyze both leadership practices in their multi-level contexts in general, and how leaders and followers perceive and describe leadership in networks and clusters in particular. In order to give the interviewees a chance to bring up the issue themselves, we avoided mentioning leadership in the first half of the interview. Thereby it was possible to avoid the gathering of mere "presentational data" (Van Maanen, 1979) that are particularly likely to be evoked in interviews on value-loaded research topics like leadership (Conger, 1998). 
In addition to the interviews, a broad range of documents (such as strategy papers, newsletters, roadmaps, and reports) provided by cluster representatives were analyzed as background information. Moreover, in all but one case (Scotland) it was possible to observe meetings and workshops. This not only compensated for the rather small number of interviews in one case (West Midlands) but also allowed us some helpful cross-validation.

--- Insert Table 1 about here ---

The interpretive methodology adopted in the analysis of the data was, within the limits of an emergent comparative case study design, as far as possible, sensitive to the constitution of leadership practices in time-space. Beyond this, it has similarities to the work of Hardy, Phillips and Lawrence (2003) in the development of categories for understanding interorganizational collaboration; and Lawrence's (2004) process of iterative reflection in the development of theory for comprehending membership dynamics in professional fields. Data from the research sites were abstracted and organized in categories, by using structurationfiltered understandings of leading (in) clusters that focus on the role of cluster rules and resources and regionalized locales - combined with some very basic concepts from leadership theory (Bass, 1990; Yukl, 2006) and, in particular, from theory of leadership in collaborative networks (Huxham \& Vangen, 2000, 2005). The development of the categories was stimulated by these theories but subjected to an iterative process of contestation and confirmation in which we moved reflectively between the data and the developing concepts until a saturation level was achieved (Suddaby, 2006). 


\section{Comparing leadership practices in the four photonics clusters}

The detailed analysis of our data reveals that individuals, and sometimes organizations, are recognized as subjects and/or objects of leadership in the four photonics clusters studied. ${ }^{2}$ It also shows that leadership practices in clusters - as in organizations - are concerned with motivating, involving, empowering, mobilizing, controlling, manipulating and so forth in order to make things - for instance a project-based collaboration among cluster members happen (Huxham \& Vangen, 2005). Nevertheless, leadership as reflexive structuration in these contexts varies considerably. This variety is unsurprising given both that the leading actors - individuals as well as organizations - are different with regard to their leadership capacity and capability and the regional clusters differ with regard to the contexts they provide.

\subsection{On the differences of the contexts and leadership practices}

Though all four clusters are at the forefront of the field of photonics, they are quite diverse with respect to geographic scale and economic size, dominant cluster rules and endowed cluster resources (see Table 2 for details). Moreover, they have very distinct, idiosyncratic histories. However, they all involve considerable complexity and ambiguity as evidenced in, for example, the sheer number of organizations involved, the geographic scale, and the blurred cluster boundaries. In this regard, regional clusters are likely to involve even more leaders than other inter-organizational contexts (e.g. Osborn \& Marion, 2009), therefore being plagued by ambiguous leader-follower constellations, a diverse set of micro contexts, and unclear measures of success.

--- Insert Table 2 about here --- 
Leadership practices in the Southern Arizona as well as the West Midlands cluster are of a centralized yet quite personal nature. In both cases, "district champions", individuals with a strong regional industry background, have been in charge of initiating and of developing the cluster for quite some time. In Southern Arizona the same person has been the champion for fifteen years. Quotations like: “He's a man on a mission” by a representative of the Arizona Department of Commerce or "He's very much pushing Tucson as Optics Valley" by the then president of the Optical Society of America and a former director of the Optical Sciences Center in Tucson support the notion of a rather centralized and personal leadership in the Southern Arizona cluster even though it has become slightly more distributed over the last few years:

"In the last few years [...] the two co-chairs have an increasing role or an increasing level of activity in so far as coordinating the activities here locally or in the region and within the state is concerned?"

(Regional Development Agency Representative)

All interviewees in Southern Arizona indicated that leadership there is attributed to a rather small group of individuals, most importantly to the champion although, as a research organization representative put it, "there are now some others". While financial cluster resources were extremely scarce, the cluster champion personally marketed Tucson as 'Optics Valley' and organized cluster events, thereby controlling to a significant extent the issues discussed and the people invited to take part in cluster activities.

The West Midlands case is similar, but here the champion holds a formal appointment with the NAO. Over the last couple of years he has increasingly taken on the role of the leading organizer of cluster activities and actively and reflexively drives the structuration of the cluster towards a market-orientation, aiming at becoming financially self-supporting: 
"On an operational level there is myself, who basically manages the network and I suppose operates in the director's capacity without being called the director. So basically I am the leader"

(NAO Coordinator)

This is supported by the view of others in the cluster. The development of the West Midlands cluster has largely been achieved through dyadic collaborations with half a dozen representatives of member organizations, with little institutionalized support. Though (financial) 'cluster resources' are available, 'cluster rules' have hardly emerged or been formulated. This means that the reflexive practice of leadership pretty much depends on the initiative and energy of the individual leader who thinks that he has "to be pro-active in making these things happen" (NAO Coordinator). Given his formal position, the leader of the West Midlands cluster, in his own view, has to coordinate the activities only with the chief executive of Birmingham Technology Limited, the formal organization that supports central facilities (Aston Science Park) and the cluster association (Photonics UK). However, six or seven special interest groups are in the planning stages and cluster leadership is therefore likely to become rather more distributed, as representatives from several member organizations, especially larger firms, will become involved in leading the cluster by means of a 'cluster steering group'. Such a reorganization towards a more distributed structure would be likely to change the view of some cluster members that the present cluster leadership is "topdown, not bottom-up, and non-representative” (SME representative).

The Scotland case is also characterized by identifiable personal leadership, although it seems to be of a significantly more embedded nature. The main instrument used to 'embed' the cluster leadership in this case is an industry association, the Scottish Optoelectronics Association (SOA), with its board, council and member structure, which seems to make the leadership more formalized. However, this embedding contributes to a fuzziness about the cluster leadership role because there is not a complete overlap between the SOA and the 
cluster. In consequence, the leadership role in this cluster is surrounded by more ambiguity than in the other three clusters.

These loosely overlapping, rather decentralized structures contribute to the reason why at least some cluster members lament a "lack of leadership" (Research Organization Representative) in the Scottish cluster. Furthermore, leadership also appears to be distributed and, for that reason alone, more fuzzy for a number of additional institutional reasons. One is the active (yet mainly funding) role of a regional development agency (Scottish Enterprise) in developing the cluster, by supplying resources and then influencing the use to which these resources are put. Another is the range of interfaces and interactions with relevant technical bodies, such as the UK Consortium for Photonics and Optics (UK CPO), the Scottish University Physics Alliance (SUPA), and the Association of Industrial Laser Users (AILU). These bodies also interconnect with a number of other relevant collaborations such as UK Government Knowledge Transfer Networks, and 'Faraday' Partnerships, further extending the distributed web of influences upon the Scottish cluster. Hence, the following view is typical of those of many cluster members:

"I would say leadership in the cluster is fairly distributed. It's not centrally managed or even focused. The leadership is quite diffuse"

(Large Technology Firm Representative)

It is perhaps for this reason that one of the interviewees aimed to organize his 'own' technologically more focused sub-cluster of small and medium-sized firms in the vicinity of his research institute. In this way, with the involvement of others, he aimed to "fill the leadership gap" (Research Organization Representative) that others have also observed. However, this perception may well be related to the large size of the organization this interviewee is working for. Nevertheless, leadership in the Scottish cluster seems to be 
significantly more distributed and formalized - i.e. an organized and organizing activity than in the West Midlands and Southern Arizona clusters.

The last of the four cases, the emerging photonics cluster in Berlin-Brandenburg, is rather different from the others. The leadership of this cluster has been planned and is far more formalized and institutionalized than in the other three cases. The organization representing the cluster is a legal body, a registered association (a Verein labeled OpTecBB), which by German law has a board and ordinary members that take an active part in decision-making, at the very least by participating in the annual meetings and (re-) electing the board. The board in the Berlin-Brandenburg case represents elected members as well as the four special interest groups that were organized right from the beginning, involving members from both societal spheres: the economy and science. So leadership at the board level is already quite distributed and represents different interests in the cluster. Additionally, a significantly larger number of members undertake leadership activities than in any of the other clusters, particularly in relation to special interest groups which have been integral to the cluster from the beginning. Comparatively, leadership in the Berlin-Brandenburg case can be understood as rather formalized and practiced as an organizing activity.

In addition to the formal leaders, a number of leaders can be identified in the cluster who have no such formal roles but are nevertheless involved in the reflexive structuration process. This is particularly the case in the competence centre, Optics Rathenow, which nicely illustrates the issue of leading in a cluster. This is a group of about 20 ophthalmologic companies located some $80 \mathrm{~km}$ outside Berlin's city centre. Similarly, operating in the field of laser materials processing, there is a group of companies which has its own association (Laserverbund). Even though this association has been quite active in the cluster, its representatives have no formal leadership role within it: 
"There is also the Laserverbund. [...] they also organize working groups [in laser technology] and exchange certain ideas of the technology and its application, they organize visits to companies and organize workshops, but there are no common activities [with $\mathrm{OpTecBB]}$ "

(NAO Coordinator)

"The connection between Laserverbund and OpTecBB is relatively weak. [... partly because] we have a much simpler structure. Here the CEO or the director of the board decides. [...] That way we have a lot more freedom"

(Laserverbund Coordinator)

In fact, in Berlin-Brandenburg a number of engaged and active participants are still not integrated within the official leadership structure of the cluster represented through the Verein. So, for both emergent and deliberate reasons, leadership is significantly more distributed in this case when compared to the other three situations. Asked who leads the cluster, several agents rather than one person or one organization have been mentioned by the head of the NAO, the members of the cluster board, and by ordinary cluster members. These also show up in a structural network analysis as central actors of the cluster (Lerch, Sydow \& Provan, 2006).

\subsection{Towards a typology of leading (in) clusters}

Summing up, the four cases studied can be placed in a three-dimensional typology as shown by Figure 1, which comprises three distinct, yet continuous dimensions which characterize leadership as an organizing activity or, to be more precise, as a cluster management practice. The first two of these dimensions are often discussed in the literature on leadership in groups and organizations, but have different implications in inter-organizational contexts, and particularly in regional clusters. The third dimension is only relevant to research on leading inter-organizational arrangements and reflects the multi-level character of research in such macro contexts. All three are compatible with a structurationist understanding that conceives 
these dimensions both as structural properties 'guiding' leadership practices and as outcomes of these very practices. These dimensions provide the first elements of a middle-range theory of leading (in) clusters that is fundamentally informed by this understanding. As such they draw upon the concrete leadership practices that have been reported above and influence the multi-contextual praxis of regional clusters. Nevertheless, it only touches the surface, and bundles of leadership practices, contested or not, are likely to - and as our study shows - do lie beneath it.

Figure 1 Dimensions of leadership: insights from four clusters

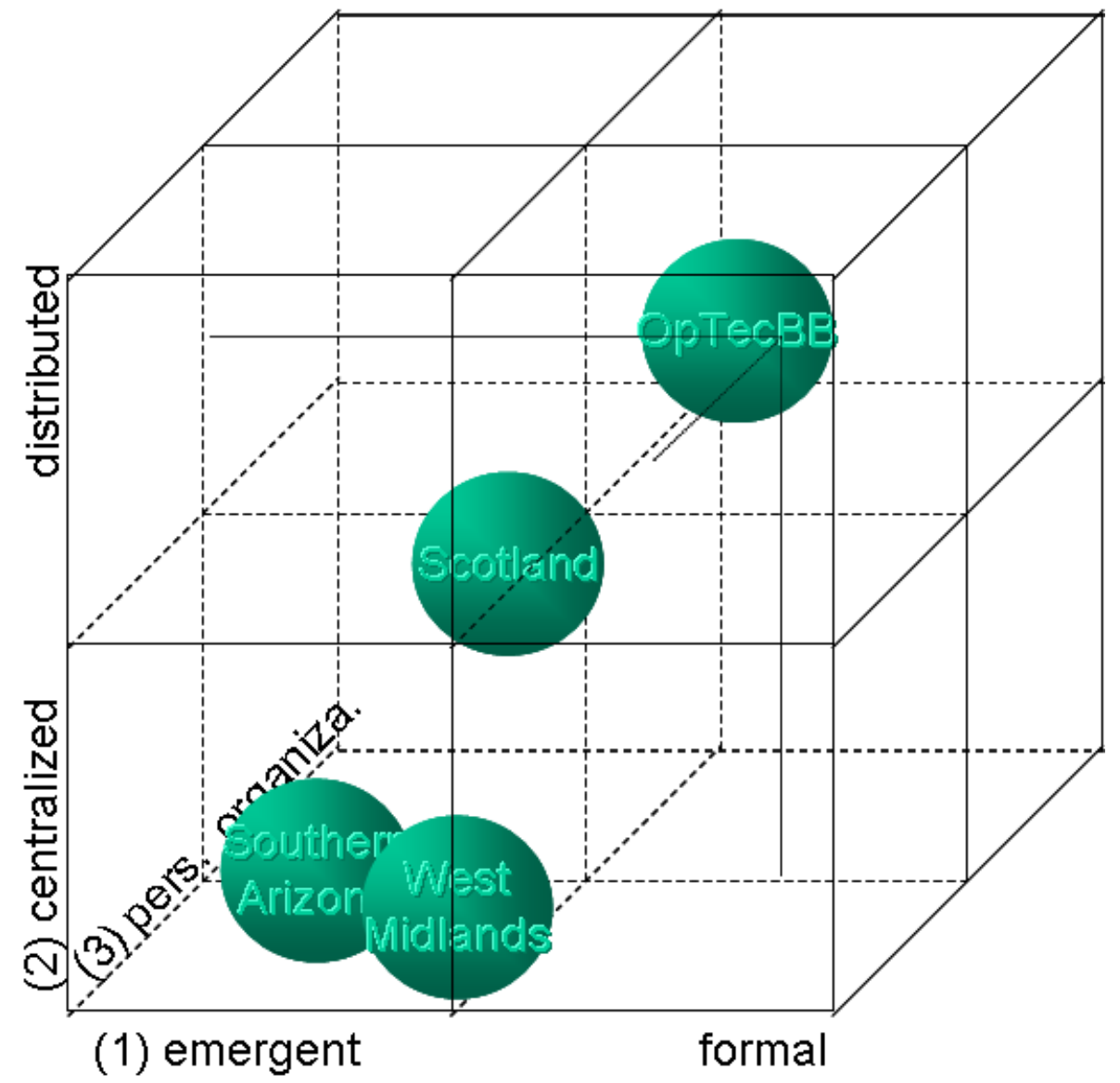


1) As in less complex organizational contexts (e.g. Balkundi \& Kilduff, 2005) leadership in clusters, even if conceived as reflexive structuration, may be either formally organized or of an emergent/ad hoc/informal nature. This may be true for leading a cluster as for leading in a cluster. In the particular context of a certain cluster, formality may be evident, for example within a cluster board structure, whereas emergent leadership may be exemplified by an actor simply taking the lead in a collaborative project, a more complex sub-network, or the cluster itself. Notwithstanding that in most regional clusters both kinds of leadership will be relevant, one may be more dominant than the other.

2) Also as in simpler, less dynamic and ambiguous organizational contexts (e.g. Bryman, 1996; Gronn, 2002; Pearce \& Conger, 2003), leadership in clusters can be either of a more centralized or distributed, dispersed or shared nature. Again this may apply to cluster leadership as well as to leadership in clusters, the latter being illustrated best by the BerlinBrandenburg case with the ophthalmologic sub-cluster in Rathenow. However, in the context of clusters, enactments are not always as might be expected. For example, despite their principally polycentric character, centralized leadership in network forms of organization is actually quite common. Even in arrangements where equality might be the expected norm, such as Italian industrial districts, clusters often seem to be led by one or more centrally positioned organizations or individual actors who act on behalf of these organizations (Lorenzoni \& Baden-Fuller, 1995; Boari \& Lipparini, 1999; Antonelli, Moschera \& Mollana, 2006; Nosella \& Petroni 2007).

3) The third dimension is concerned with whether leadership is attributed to persons or organizations. This dimension too has to be considered with respect to both, leading clusters and leading in clusters. For example, in setting up a cluster initiative often there is one single person, a "clusterpreneur" who takes a lead for the whole cluster. In other instances such an 
initiative is set up by government (agencies) at various levels (Sölvell et al., 2003: 29) or by another lead organization from the economic rather than the political sphere. In most clusters, both types of leadership are likely to be relevant and to interact. But again, one kind of leadership may be more relevant than the other, depending not least on the structures of the cluster and how they are enacted by the leaders.

While the leadership practices observed in the four photonics clusters seem to cover the whole spectrum in terms of the first two dimensions, the organizational nature of cluster leadership is less prominent in the data, partly because interviewees - in line with attribution theory (Calder, 1977; Bresnen, 1995) - apparently conceive of leadership as being of an individual character, but also because there were no powerful organizations leading in all four clusters (although we have observed such strong organizational leadership in another German cluster where leadership actions are clearly attributed to a hub firm in the network). This, however, does not imply that cluster leadership - or leadership in clusters - is not organized or institutionalized. From a structuration perspective, institutionalization is not only a question of meanings and values (Selznick, 1957). Rather, this process is entangled with the resource character of institutions, conceived here as the more enduring features of social life or practices deeply sedimented in time-space and widespread among the members of social systems (cf. Giddens 1984: 24). An example of such a practice is the stipulation of collaboration even with competitors when the cluster has developed to a certain level of maturity. Hence, the institutionalized nature of leading (in) clusters that will be elaborated in the next sections is reflected in all three dimensions; it is simply not attributed to organizations. However, rather than focusing on the impact of institutions on leadership practices (Selznick, 1959; Biggart \& Hamilton, 1987), the following discussion centers around the complementary question of how institutions that either support or undermine leadership are produced, reproduced and, eventually, transformed by these very practices. 


\section{Doing leadership in clusters and the relationship with structures}

The notion of "doing leadership" (Huxham \& Vangen, 2005) highlights the everyday practice of making things happen by leading individuals and organizations. Conceived from a structuration perspective and applied to a cluster setting, when doing leadership one would expect agents - i.e. leaders - to refer mainly to cluster rules and resources and reproduce or transform them via these very practices. These leadership practices are likely to be found in particular locales that are physical or virtual social spaces that not only provide the spatial context for interpersonal and/or inter-organizational interaction (implying the presence or absence of actors) but enable or constrain this very interaction (cf. Giddens, 1979, 1984: 118119; Pred, 1990).

\subsection{Locales and relations for doing leadership}

Some regional clusters are well known for the diversity of locales they offer for social interaction (e.g., Saxanian, 1994). In the clusters investigated, leadership as reflexive structuration is to be found mainly in locales such as conferences and workshops, seminars and meetings, but also in everyday business communications and localized interactions as well as in strategic road-mapping activities. ${ }^{3}$ Several of these locales were specifically created by cluster leaders or leaders within the cluster in order to have spaces available where they can lead and/or present themselves as leaders.

Data from the Arizona case indicate a rather broad range of locales where leadership 'happens', including a range of physical arenas like workshops and regional or state policy meetings, exchanges universities or cluster business luncheons. Other locales - of a virtual 
nature - for doing leadership include emails and newsletters. The doing of leadership in such locales - for example, getting up in front of a group, making comments, taking positions, explaining the necessity, creating a sense of exclusivity, communicating selectively and generally - as much as the organizing and embedding of leadership involves the utilization of complex relational webs. These typically incorporate several - individual and organizational - core actors within the cluster, but also with some important external stakeholders. For instance, in the Southern Arizona case the cluster leader uses his well established relational web with funding agents for the acquisition of additional resources that, in turn, makes it easier for him to sustain or even augment his leadership role within the cluster:

"The Desert Angels are very aware; they have invested in some of my ventures and in others. I am a Desert Angel. I am also on the advisory board so that when they get into optics stuff, since most of them don't understand it, I am there to explain it. And that helps."

(Cluster Champion)

With regard to the relations of cluster leaders with less central cluster members, the four clusters differ significantly. The respective network of relationships seems to be much denser in Berlin-Brandenburg and Southern Arizona than in the two British clusters. However, only in the German case do all actors, including even those at the periphery, think of themselves as members of the cluster. A reason for this finding might lie in the evolving "regional industry identity" (Romanelli \& Khessia, 2005) in Berlin-Brandenburg that, so far at least, does not seem to have emerged in the two British cases and is restricted to the core members in the U.S. cluster.

In all these locales and mainly based upon relations, leadership power is generated, concentrated and also possibly opposed, but may also go unacknowledged by followers. The powerful practices are enabled, partly because they are also constrained, by relationships and other structures of the cluster and beyond. The distribution of these practices across the 
different locales in time and space can be characterized as the "regionalization" (Giddens, 1984: 119-122) of leadership in the cluster.

\subsection{Leading by enacting cluster rules and resources}

Despite this prominent relational aspect, cluster leadership and leadership in clusters as an organizing activity also involves referring to cluster rules and resources in particular practices and, thereby, embedding such (leadership) practices more deeply within networks in clusters. Like any action, leadership relies on structures, that is, on rules and resources or - to be more precise - on rules of signification and legitimation as well as on resources of domination (Giddens, 1984). The four clusters differ quite significantly with respect to the sets of rules and resources which can be and actually are enacted in the doing of leadership. In order to provide a deeper understanding of the processes involved, we focus in this section on the role of resources in the structuration process of leading (in) clusters in the four cases. Because of the recursive relationships between rules and resources (Giddens, 1984), agents can only effectively refer to the latter and lead if the respective practices make sense to others and are considered as legitimate in the particular cluster or network context.

For example, in the West Midlands generous public funding seems to be by far the most important resource on which cluster leadership practices are based, whereas this is almost absent in the Southern Arizona cluster where leadership is largely based on the voluntary provision of private resources in the hands of the cluster champion who is leading the cluster. The Scottish and the Berlin-Brandenburg clusters exhibit a position in between these two extremes concerning the level of their funding endowment. The Berlin-Brandenburg cluster has less guaranteed (regional) public funding to develop the cluster than in the West Midlands. However, in Berlin-Brandenburg the regional public funding is extended 
considerably through both the membership fees generated by cluster members and federal government funding. By comparison, the financial "cluster resources" that support cluster leadership in the Scottish case are rather distributed. In the past, the referent organization has received sporadic governmental funding for developing the cluster, but a constant stream of financial resources as in the case of the West Midlands and Berlin-Brandenburg is absent, and the main sources of finance are membership fees and revenues generated by specific cluster activities. These activities are often under the umbrella of other national projects or programmes, contributing further to the distributed leadership character of the Scottish photonics cluster.

Generally, public funding and other financial resources are among those that can be used most flexibly by cluster leaders. As allocative resources of domination, they are a prime basis of power and influence for those who can decide over the disposition of the funds in cluster development; especially, if this is done in a way that makes sense to and is acceptable for the other cluster members. However, other resources are also considered to be important for executing cluster leadership, including technical and marketing expertise, knowledge about other organizations' competencies, relational links to specific organizations, and last but not least social skills like the ability to partner. In contrast to financial resources, these latter resources are seen to be of a more personal nature:

"[name] heard that I had good connections in Singapore in the optics industry there. And he asked: 'Do you have any people there that you could get me in contact with? [...] and he went down there on short notice and he has a wonderful business development success”

(Cluster Champion, Arizona).

However, it must not be overlooked that this and other persons often have these contacts because of their organizational roles. In turn, many organizations would not have the ties they maintain without particular individual actors. 
In the Berlin-Brandenburg case, for example, resources of domination result from the expert technological, market and (inter-)organizational knowledge of the leaders and are applied in strategic road mapping and master planning processes. ${ }^{4}$ In the roadmap or master plans technological and market alternatives are formally fixed. Thereby, the decision of which technological alternatives to follow and which organizations to include, is powerfully made by the cluster leaders. Because there are several epicenters of power within the BerlinBrandenburg - "regionalized" - optics cluster this is a distributed process, albeit organized within the formal structures of the OpTecBB-Verein. The roadmap or master plans (as structures) thus are, on the one hand, the result of leadership practices within the cluster. On the other hand, the actors involved can decide about the selection or exclusion of partners to form the cluster with a certain degree of freedom. The road mapping and master planning thus become power-laden cluster management practices. In short they are not only a result but also an important medium of leading (in) clusters conceived here as reflexive structuration.

Expert knowledge is also a relevant source of domination in other clusters. In the Southern Arizona case the cluster champion uses his exclusive knowledge about the technologies developed in the region, about the (world) markets, as well as about the cluster members' capabilities to inform actors within and outside the cluster and especially the financing community such as venture capitalists. The Optics Report for example, which is edited by the cluster champion, or the presentations about the optics cluster to the venture capitalist community in Southern Arizona, have become cluster institutions. As such, they are the result and media of cluster leadership. They appear as resources of domination in the sense that, for example, the report includes and excludes specific information that is filtered and controlled by the editor - the cluster champion. By subscribing, reading and using the provided information, cluster members begin to be led. However, cluster members might also 
transform the leadership practice, for example by supplying information to the report and making sure that the information is included in the newsletter or presentations. The language used in the newsletter as well as in the presentations to potential financiers needs to be understood on the one hand by the optics community and on the other by the financial and political community; this language therefore becomes a bridging facility in the structuration process. Actors who are proficient in the use of this specific 'bridging' language hold an important resource of domination.

In Scotland, and even more so in the West Midlands case, the bundling of rather distributed expert technological, market and (inter-) organizational knowledge appears to be more problematically employed in leading the cluster because cluster actors appear to be, at least at times, unaware of other relevant actors. In addition the Scottish optics community, despite an installed optics association, did not act as a cohesive and united agglomeration. Instead the distributed character not only of the optics actors but also of the resources of domination can be seen as an indication of more distributed leadership within the cluster. Leading actors here were more concerned with either leading their research groups and partners (within the cluster and beyond) even perceived themselves as being just a member of a network that is being led by some other actor. Nevertheless expert knowledge was applied here too as a resource of domination in doing leadership in the cluster, though to a very limited extent.

These resources - like the financial endowment of the clusters, expert knowledge, or the networks of relationships within and beyond the cluster - are produced, reproduced and, eventually, transformed as cluster structures by the very relational leadership action that 'makes things happen'. This, however, is not only true with regard to the structures of the cluster but also with regard to some more macro- and micro-level structures such as a federal or regional funding program or management time respectively. In none of these cases, 
however, would one assume that the resources 'determine' leadership practices. Rather much depends on how leaders - as knowledgeable agents - enact these structures. Finally, it must be noted that resources of domination develop their potential only when individual or collective agents refer to them in a manner that is in accordance with the rules of signification as well as the rules of legitimation prevailing in a system. For the theory of structuration, more than any others, emphasizes the recursive interplay between these aspects of structures - and the respective aspects of social actions (e.g. Giddens, 1984; Barley \& Tolbert, 1997; Sydow \& Windeler, 1998; Pozzebon, 2004).

\section{The silent cry paradox and 'managing' it via organizing for leadership}

Summing up our analysis so far, leadership of and in regional clusters is manifest in particular leadership practices that can be identified in distinctive locales as well as in everyday interactions. Via these practices, leading individual and organizational actors - no matter whether formally appointed or informally emergent, within centralized or decentralized structures - refer to the rules and resources of the cluster they lead (in). Similarly, they also refer to those of more micro- and more macro-level systems and, thereby, reproduce or transform these structures. The development of leadership is thus recursively linked to the development of the (networks in the) cluster. The ambiguity, diversity, dynamism, and complexity of the cluster context is, at least from a structurationist perspective, a structural condition as well as an outcome of these very leadership practices. Together with very specific historical, political and cultural aspects of the context, the particular technological heritage of the region for instance (Saxanian, 1994), this leads to significant differences in leadership practices among the four photonics clusters studied. 
On the surface, despite this significant difference in leadership practices conceived here as reflexive structuration, the perceived need for leadership per se seems to be evident, for example

Yes [, there may be a lack of leadership].... You can always say that with better or more leadership, then things would be better.

(Large Firm Representative, Scotland).

However, one surprising outcome of the analysis is that, if not specifically prompted, discourse about leadership did not feature in network or cluster talk at all. This was true for all clusters despite their different profiles and corroborates the earlier finding by Huxham and Vangen (2000: 1162) that in collaborative networks there is "very little spontaneous use of the term ('leadership')" (our emphasis). In addition, where we were able to observe leadership in different locales, it was not mentioned. There may be at least four reasons for this: leadership as reflexive structuration is completely absent in these systems; membership in these regional innovation systems is only of marginal interest to an individual or an organization; leadership, though potentially identifiable in a cluster, is somewhat invisible; or cluster members simply do not like to talk about leadership and, in particular, about being led.

The first two reasons can be dismissed. With regard to the possible absence of leadership in clusters, ${ }^{5}$ we have demonstrated that leadership can not only be identified in these systems, but also characterized on at least three dimensions. In relation to the interest of members in such regional innovation systems, we have found that most of those interviewed - including those at the periphery - have an interest in the cluster.

The final two reasons require more detailed consideration. With regard to invisibility, we demonstrated that cluster leadership, less so leadership in clusters, is indeed, more often than not, hardly visible. This does not necessarily evidence a lack of (adequate) leadership but 
rather its hidden-ness behind structures - despite its reflexivity from the perspective of the leading individual or organization. In all four cases, there was some confusion about the boundaries of the cluster to be led, since these were not coterminous with the relevant associations providing the legitimating framework for leadership in each case. There was even more confusion about cluster governance in the Arizona and Scotland cases, because the formal organizations were set up to govern an industry rather than a regional cluster. In the Berlin-Brandenburg and the West Midlands cases, the formal organization was deliberately set up to represent the entire cluster. In Berlin-Brandenburg, however, they have built cluster rules and used cluster resources - for example, the roadmaps and master plans which govern the inclusion and exclusion of particular firms - that "mask" leadership interventions and, in this case, act as "substitutes for leadership" (Kerr \& Jermier, 1978). Furthermore, in the West Midlands case the introduction of more distributed governance structures - such as special interest groups - may in the future lead not only to greater distribution but also masking of leadership.

The apparent avoidance of talk about leadership in clusters may actually be strongly connected to the invisibility issue. People, as previously argued, expect to see leadership enacted by individual persons, but in clusters it is evidenced in various different guises. Firstly, it is often enacted through cluster structures, i.e. rules and resources. That is to say, leadership - as an organizing practice - becomes, not despite but because of its reflexivity, institutionalized by being hidden behind structures. Even in the one case where there seemed to be some recognizable individual leadership - the Arizona case - this had the effect of both masking other forms of leadership and removing the notion of leadership from the agenda; it was unquestioningly assumed to be embodied in a charismatic individual, who was actually perceived as a facilitator rather than a decision maker. Secondly, leaders, especially if successful, "make things happen" via the actions of others, and thus are not credited with the 
outcomes. Finally, the partially emergent character of leadership in these and other situations (see Fleming \& Waguespack, 2007) means that cluster members are not in a position to articulate the actuality of leadership in familiar terms, or to have a stable perspective on how things are made to happen. For example, the emerging distributed structures in the West Midlands are only engaging and recognizable to those intimately involved, and they are also processually indeterminate; they are therefore hard to describe for both of these reasons. Similar observations could be made, to a degree, in relation to all of the clusters. This interpretation corroborates the discovery of the adequateness of "covert leadership" (Mintzberg, 1998) - rather than absence of leadership - in managing professionals.

There may also be a tacit reluctance to verbalize issues of leadership. Cluster members small and medium-sized firms that almost always make up the majority of organizations in clusters (including the four photonics clusters we studied) - usually do not have a capacity for cluster leadership and may not like to talk about leadership since they would thereby denote themselves as being led.

These two reasons, the relative invisibility of cluster leadership as well as the reluctance to verbalize leadership, thus provide explanations for the paucity of leadership discourse despite an underlying sense that cluster leadership is practiced and enhanced leadership would be helpful. There is a 'cry for leadership', although it is a cry that generally remains silent:

the companies themselves will not manage this collective problem because everybody is too much involved in his day to day business. Now, at the next 'Networking Day' all the facts need to be put on the table for the first time and the next task really would be to nominate someone who is in charge. Someone who needs to push this more“

(Small Firm Representative, Berlin).

Like every paradox or dilemma, the silent cry paradox is conceived of as involving seemingly contradictory concepts that nonetheless exist together in tension (Poole \& Van de Ven, 1989; 
Huxham \& Beech, 2003). This paradox, which may characterize most regional clusters, can certainly not be resolved, but has to be "managed" inside the system. As the data from the four photonics clusters suggest, the dilemma can be dealt with by reflexive structuration in terms of adopting a style of leadership that actually is little visible, emphasizing the continuous building, maintaining or institutionalizing of structures by avoiding direct ad-hoc interventions of leading individuals or organizations into ongoing practices. This sounds like a new "one best way" recommendation that falls back behind Fiedler's (1967) contingency theory of leadership and other approaches that highlight the importance of context. The immediate need for institutionalizing leadership, however, clearly depends upon contextual circumstances - and so do the degree and the means to realize it. For instance, a comparatively old and established innovation system like the Southern Arizona photonics cluster seems to be well advised to develop a somewhat more institutionalized and differentiated approach to leading the cluster. Then the pronounced personal leadership of this cluster could rely more on institutions and, thus, become a little more independent of the particular person leading the cluster. In addition, it would be less difficult for any individual succeeding the present charismatic leader who has built the region into one of the leading photonics clusters in the world over a period of more than 15 years. On the other hand, institutionalizing cluster leadership in this case will be particularly difficult, given the enduring scarcity of cluster resources.

Another recommendation for 'managing' the silent cry paradox would be to remain sensitive not only of the role of leadership in day-to-day interactions, but also to specific leadership locales where reflexive structuration takes place. Workshops, conferences and other types of meetings, sometimes even email correspondence, provide unique social settings in which to become visible as a leader - or to hide leadership behind structures. 


\section{Conclusions and limitations}

This paper provides a first study of leading (in) regional clusters and, thereby, responds to the recent call for leadership research in more macro contexts. At the same time, it offers insights into network and, in particular, cluster processes that have hardly been studied from a leadership perspective, not least because they have been somewhat carelessly labeled as selforganizing (Cooke, 2007). To both ends leading (in) clusters has been conceptualized as reflexive structuration, thereby introducing a fresh theoretical lens to research on leadership in general and in relation to clusters in particular; a lens that is particularly sensitive towards, first, structured and structuring processes driven by leaders as knowledgeable agents and, second, the multi-level nature of such macro contexts. In addition, adopting a structuration perspective, sensitive to the importance of social relationships, our work may inform emerging relational leadership theory (Uhl-Bien, 2006). More so than in most other studies of leadership in macro contexts to date the importance of relationships has been acknowledged in this study. What is more, relationships are revealed not only as an outcome, but also as a means of (relational) leadership, although admittedly there is also room for considering a social network approach in this regard (see, however, Balkundi \& Kilduff, 2005).

In sum, our study shows that leadership practices in and of clusters are identifiable and that the practices vary substantially in and across the four photonics clusters investigated. Nevertheless, we can make out at least three dimensions upon which the practices can be mapped. While the emergent-formal and the centralized-distributed dimensions showed clearly in the cluster discourses, the individual-organizational distinction is not well articulated by cluster members, even though it is evident. This result may reflect the observation that action in general and leadership in particular tends to be attributed to persons 
rather than organizations or other social systems, even when broader collective levels have some explanatory utility. Furthermore, we have identified cluster rules and resources that complement relationships as important points of reference for leading (in) clusters. Taking these into account also ensures that leadership is not only conceived as being based upon and targeting interpersonal relationships, as is common for most approaches to relational leadership to date, but is also to be conceptualized as structurally embedded and structurereproducing. For example, shared views about the cluster purpose, as well as artifacts like road maps and master plans, not only support and constrain leadership but are more or less reflexively reproduced or transformed via leadership practices. Moreover, clusters provide a considerable breadth of locales for leadership, some of which potentially make leadership more visible to cluster members.

Nonetheless, we found a cry for leadership in clusters, because this potential was not fully recognized in all four clusters. This 'cry', however, was only expressed silently. That is, unless prompted, there was little explicit use of the notion of leadership despite the acknowledgement of the undesirability of it absence. Finally, we found good reasons for a cry for leadership in clusters that remains silent, because leadership as reflexive structuration is either executed in a more indirect and institutionalized way - via cluster structures - or because most cluster members do not like to be led even when they feel a strong sense that things should be made happen. Without doubt, this silent cry paradox makes the study of leading (in) clusters difficult. This is particularly the case when the research is concerned to avoid producing another version of "leadership romance" (Meindl, Ehrlich \& Ducherich, 1985), i.e. the tendency to idealize individual leaders not only at the cost of their followers but also their organizations and, thus, to attribute much greater influence on outcomes to them as individuals than they actually have (see also Crevani, Lindgren \& Packendorff, 2010; Fairhurst, 2007). However, we believe that the silent cry paradox is an empirical phenomenon 
to be observed in regional clusters and not a methodological artifact reflecting the difficulty of getting hold of leadership processes in cluster contexts. In any case, this finding complements nicely the leadership romance critique. Though, while the cry for leadership may usually be silent in clusters, this may well be different in times of crisis and change. ${ }^{6}$

The study also shows that clusters provide a unique context for leadership that is characterized by ambiguity, diversity, dynamism, and complexity; the genuine failure of hierarchical fiat; and the importance of networks of relationships. Most importantly, however, this context is of a multi-level nature that - in addition to the organizational level has to take into account the network and cluster levels. Beyond the findings that leading (in) clusters is likely to differ from leading (in) organizations as well as from network/cluster context to network/cluster context, that cluster structures and specific locales matter, and that the silent cry paradox is omnipresent (at least apart from times of turbulence), this uniqueness makes it systematically difficult to draw generalized conclusions from this research. Nevertheless, in discussing the limitations of our research, we will draw some conclusions for future leadership (and cluster) research and practice.

Our study of leadership processes and practices was confined to four photonics clusters in England, Scotland, Germany and the United States. Although these are leading clusters in the field, the insights gained by studying them may be limited to high-tech or science-based clusters that are, by their very nature, characterized by rather intensive inter-organizational interaction across societal spheres. In order to enquire more into the possible general applications of our findings, future research on leading (in) clusters, therefore, would have to include clusters in other technological/organizational fields (including low-tech fields). With regard to the generalizability of the findings it may also be useful to compare leadership in high-tech clusters with those in high-tech companies, which seem to provide different but 
similarly ambiguous, diverse, dynamic, and complex contexts (Alvesson \& Sveningsson, 2003 ) but lack networks and clusters as additional 'layers' in multi-level contexts.

The methodology of this study was mainly confined to semi-structured interviews with selected individuals acting in these clusters either as leaders or as followers. While interviews are valuable sources of insight, they tend to elicit the description of structures without investigating how they affect - and are affected by - real practices. In three of the clusters we were at least able to circumvent this limitation by some participative observation (cf. Conger, 1998). With regard to cultural differences such interviews may be of limited value regarding the description of (deep) structures (rules of signification and legitimation, to be more precise). This is one of the reasons why we have not engaged in international cultural comparison of leadership practices in our research. Future leadership studies of this type of context, therefore, could not only turn to other fields and possibly include the cultural dimension, but also take a more ethnographic approach, by observing more closely and in depth selected leadership practices in locales that are specific to networks and/or clusters and to cross-validate them systematically with interview data. Such studies, definitively allowing for an "inquiry from the inside" (Evered \& Louis, 1981), might also provide more exact insights into the distinction between leadership in and of clusters. Moreover, if carried out over a longer period of time, the identification of specific leadership practices as well as the investigation of their reproduction and eventual transformation would be possible.

A more longitudinal study approach might also help to reveal whether and when the recursive processes of structuration lead to fixed or quasi-fixed developmental paths of leadership practice. Such paths would always imply a certain path dependence and, therefore, at least a potentiality of leading finally into a "lock-in" (David, 1985). This path-character is clearly demonstrated in the Southern Arizona case, where the very personalized nature of cluster 
leadership (and the respective lack of institutionalization) may cause difficulties once the present leader retires and does not have an appropriate successor. More formally, there seem to be at least three alternative pathways to organize for leadership of and in clusters, which may be derived from the present study:

1.0 Starting from a personal approach via organizing certain locales to formalized governance

2.0 Starting by setting up a formal cluster governance that, however, should be less conceived as a substitute for leadership, but rather in need of enactment, actualization, and filling with social life by leaders

1.5 Starting by creating locales that provide for an intermediate degree of institutionalization.

These pathways could and should be subject to future studies of leadership of and in clusters. At present, any plea for a careful consideration of the possibilities for a more organized approach to leading (in) clusters should take these different pathways into account, and reflect - in line with other contextual approaches to leadership (e.g. Osborn \& Marion, 2009) - upon which may be most suitable under the contextual circumstances of a particular cluster at a particular point in time - rather than recommending a new, single best way of leading (in) clusters or institutionalizing leadership of and in clusters.

\section{References}

Adams, J.S. (1980). Interorganizational processes and organizational boundary activities. In

Cummings, L.L. \& Staw, B.M. (Eds.) Research in organizational behavior 2 (pp. 321355). Greenwich, Conn.: JAI-Press.

Alvesson, M. \& Svenigsson, S. (2003). The great disappearing act: Difficulties in doing “leadership". Leadership Quarterly, 14, 359-381.Antonelli, G., Moschera, L. \& Mollana, 
E. (2006). How to save clusters from dying? Paper presented at the EIASM Workshop 'Organizing Paths - Paths of Organizing', November 3-4, 2006. Free University of Berlin, Germany.

Asheim, B.J., Cooke, P. \& Martin, R. (2006) (Eds.). Clusters and regional development. London: Routledge.

Balkundi, P. \& Kilduff, M. (2005). The ties that lead: A social network approach to leadership. Leadership Quarterly, 16, 941-961.

Barden, J.Q. \& Mitchell, W. (2007). Disentangling the influences of leaders' relational embeddedness on interorganizational exchange. Academy of Management Journal, 50(6), $1440-1461$.

Barley, S.R. \& Tolbert, P.S. (1997). Institutionalization and structuration: Studying the links between action and institution. Organization Studies, 18(1), 93-117.

Bass, B.M. (1990)(Ed.). Bass and Stogdill's handbook of leadership: Theory, research and managerial applications. New York: Free Press.

Berends, H., Boersma, K. \& Weggeman, M. (2003). The structuration of organizational learning. Human Relations, 56(9), 1035-1056.

Beyer, J.M. \& Browning, L.D. (1999). Transforming an industry in crisis: Charisma, routinization, and supportive cultural leadership. Leadership Quarterly, 10(3), 483-520.

Biggart, N.W. \& Hamilton, G.G. (1987). An institutional theory of leadership. Journal of Applied Behavioral Science, 23(4), 429-442.

Boal, K.B. \& Hooijberg, R. (2001). Strategic leadership research: Moving on. Leadership Quarterly, 11(4), 515-549. 
Boari, C. \& Lipparini, A. (1999). Networks within industrial districts: Organizing knowledge creation and transfer by means of moderate hierarchies. Journal of Management and Governance, 3, 339-360.

Bresnen, M.J. (1995). All things to all people? Perceptions, attributions, and constructions of leadership. Leadership Quarterly, 6(4), 495-513.

Brusco, S. (1982). The Emilian model: Productive decentralisation and social integration. Cambridge Journal of Economics, 6(2), 167-184.

Bryant, C.G.A. \& Jary, D. (2001). The uses of structuration theory: A typology. In Bryant, C.G.A. \& Jary, D. (Eds.) The contemporary Giddens (pp. 43-61) Basingstoke: Palgrave. Bryman, A. (1996). Leadership in organizations. In Clegg, S.R., Hardy, C. \& Nord, W.R. (Eds.) Handbook of organization studies (pp. 276-292). London: Sage.

Bryman, A. (2004). Qualitative research on leadership: A critical but appreciative review. Leadership Quarterly, 15, 729-770.

Bryman, A., Bresnen, M., Beardsworth, A. \& Keil, T. (1988). Qualitative research and the study of leadership. Human Relations, 41(1), 13-30.

Bryson, J.M. \& Crosby, B.C. (2006). Leadership for the Common Good. In Schuman, S. (Ed.): Creating a Culture of Collaboration (pp. 367-396). San Francisco: Jossey-Bass.

Calder, B.J. (1977). An attribution theory of leadership. In Staw, B.M. \& Salancik, G.R. (Eds.): New directions in organizational behavior (pp. 179-202). Chicago: St. Clair Press.

Casson, M.C. (2003). An economic approach to regional business networks. In Wilson, J.F. \& Popp, A. (Eds.): Industrial clusters and regional business networks in England, 17501970 (pp. 19-43). Aldershot: Elgar. 
Conger, J.A. (1998). Qualitative research as the cornerstone methodology for understanding leadership. Leadership Quarterly, 9(1), 107-121.

Cooke, P. (2007). To construct regional advantage from innovation systems first build policy platforms. European Planning Studies, 15(2), 179-194.

Cooke, P., Braczyk, H.-J. and Heidenreich, M. (2004) (Eds.). Regional innovation systems. $2^{\text {nd }}$ edition. London: Routledge.

Crevani, L., Lindgren, M. \& Packendorff, J. (in press). Leadership, not leaders: On the study of leadership as practices and interactions. Scandinavian Journal of Management (2010), doi:10.1016/j.scaman.2009.12.003

Danaraj, C. \& Parke, A. (2006). Orchestrating innovation networks. Academy of Management Review, 31(3), 659-669.

David, P.A. (1985). Clio and the economics of QWERTY. American Economic Review, 75 (2), 332-337.

De Rond, M. \& Bouchikhi, H. (2004). On the Dialectics of Strategic Alliances. Organization Science, 15, 56-69.

Denis, J.-L., Lamothe, L. \& Langley, A. (2001). The dynamics of collective leadership and strategic change in pluralistic organizations. Academy of Management Journal, 44(4), 809-837,

Drath, W.H., McCauley, C.D., Palus, C.J., Van Velsor, E., O’Connor, P.M.G. \& McGuire, J.B. (2008). Direction, alignment, commitment: Toward a more integrative ontology of leadership. Leadership Quarterly, 19, 635-653. 
Eden, C. \& Huxham, C. (2006). Researching organizations using action research. In Clegg, S., Hardy, C., Nord, W. \& Lawrence, T. (Eds.) Handbook of Organization Studies, $2^{\text {nd }}$ edition (pp. 388-408). London: Sage.

Eisenhardt, K.M. (1989). Building theories from case study research. Academy of Management Review, 14(4), 532-550.

Evered, R. \& Louis, M.R. (1981). Alternative perspectives in the organizational sciences. Academy of Management Review, 6, 385-395.

Fairhurst, G.T. (2007). Discursive leadership. Los Angeles: Sage.

Feldman, M. \& Francis, J.L. (2006). Entrepreneurs as agents in the formation of industrial clusters. In Asheim, B., Cooke, P. \& Martin, R. (Eds.): Clusters and regional development: Critical reflections and explorations (pp. 115-136). London: Routledge.

Feldman, M.P. \& Lendel, I. (2009). Under the lens: The geography of optical science as an emerging industry. Economic Geography. 85 (forthcoming).

Feyerherm, A.E. (1994). Leadership in collaboration: A longitudinal study of two interorganizational rule-making groups. Leadership Quarterly, 5(3/4), 253-270.

Fiedler, F.E. (1967). A theory of leadership effectiveness. New York: MacGraw-Hill.

Fleming, L. \& Waguespack, D.M. (2007). Brokerage, boundary spanning, and leadership in open innovation communities. Organization Science, 18(2), 165-180.

Giddens, A. (1979). Central problems in social theory. London: Macmillan.

Giddens, A. (1984). The constitution of society. Cambridge: Polity.

Graen, G.B. \& Graen, J.A. (2006)(Ed.). Sharing network leadership. Greenwich, Conn.: IAP.

Graf, H. (2006). Networks in the innovation process. Local and regional interactions. Cheltenham, UK \& Northhampton, MA: Edward Elgar. 
Gronn, P. (2002). Distributed leadership as a unit of analysis. Leadership Quarterly, 13, 423451.

Hardy, C., Phillips, N. \& Lawrence, T.B. (2003). Resources, knowledge and influence: The organizational effects of interorganizational collaboration. Journal of Management Studies, 40, 321-347.

Hendry, C., Brown, J. \& DeFillippi, R. (2000). Regional clustering of high technology-based firms: Opto-electronics in three countries. Regional Studies, 34(2), 129-144.

Heracleous, C. (2000). An ethnographic study of culture in the context of organizational change. Journal of Applied Behavioural Science, 37, 426-446.

Hosking, D.M. (1988). Organising, leadership and skilful process. Journal of Management Studies, 25, 147-166.

Human, S.E. \& Provan, K.G. (2000). Legitimacy building in the evolution of small-firm multilateral networks: A comparative study of success and demise. Administrative Science Quarterly, 45(2), 327-365.

Humphreys, M., Brown, A. \& Hatch, M. (2003). Is ethnography jazz? Organization, 10, 5 31.

Hunt, J.G. \& Ropo, A. (1995). Multi-level leadership: Grounded theory and mainstream theory applied to the case of General Motors. Leadership Quarterly, 6(3), 379-412.

Huxham, C. \& Beech, N. (2003). Contrary prescriptions: Recognizing good practice tensions in management. Organization Studies, 24(1), 69-93.

Huxham, C. \& Vangen, S. (2000). Leadership in the shaping and implementation of collaboration agendas: How things happen in a (not quite) joined up world. Academy of Management Journal, 43, 1159-1175. 
Huxham, C. \& Vangen, S. (2005). Managing to collaborate. London: Sage.

Jacobs, D. \& de Man, A.-P. (1996). Clusters, industrial policy and firm strategy: A menu approach. Technology Analysis and Strategic Management, 8(4), 425-437.

Jarillo, J.C. (1988). On strategic networks. Strategic Management Journal, 9(1), 31-41.

Kerr, S. \& Jermier, J.M. (1978). Substitutes for leadership: Their meaning and measurement. Organizational Behavior and Human Performance, 12(3), 375-403.

Ketels, C.H.M. (2003). The development of the cluster concept - Present experiences and further developments. Paper download: http://www.isc.hbs.edu/pdf/Frontiers of Cluster_Research_2003.11.23.pdf (July 12, 2005).

Ketels, C.H.M., Lindqvist, G. \& Sölvell, Ö. (2006). Cluster initiatives in developing and transition economies. Stockholm: Center for Strategy and Competitiveness.

Knights, D. \&Willmott, H. (1992). Conceptualizing leadership processes: A study of senior managers in a financial service company. Journal of Management Studies, 29(6), 761-782.

Krugman, P. (1991). Geography and trade. Cambridge, Mass.: Harvard University Press.

Lawrence, T. (2004). Rituals and resistance: membership dynamics in professional fields. Human Relations, 57, 115-143.

Lerch, F., Sydow, J. \& Provan, K.G. (2006). Cliques within clusters - Multi-dimensional network integration and innovation activities. Paper presented at the 22nd EGOS Colloquium July, 6-8. Bergen, Norway.

Lorenzoni, G. \& Baden-Fuller, C. (1995). Creating a strategic center to manage a web of partners. California Management Review, 37(3), 146-163.

Lundvall, B.-Å. (1992). National systems of innovation: Towards a theory of innovation and interactive learning. London: Pinter. 
Marshall, A. (1890). Principles of economics: An introductory volume. London: Macmillan.

Maillat, D. (1991). The innovation process and the role of the milieu. In Bergman, E.M., Maier, G. \& Tödtling, F. (Eds.) Regions reconsidered (pp. 103-117). London, New York: Mansell.

Martin, R. \& Sunley, P. (2003). Deconstructing clusters: Chaotic concept or policy panacea? Journal of Economic Geography, 3(1), 5-35.

Meindl, J.R., Ehrlich, S.B. \& Ducherich, J.M. (1985). The romance of leadership. Administrative Science Quarterly, 30, 78-102.

Mintzberg, H. (1998). Covert leadership: Notes on managing professionals. Harvard Business Review, 76(6), 140-147.

Nelson, R.R. (1993). National innovation systems: A comparative analysis. New York: Oxford University Press.

Niehoff, J. \& Pearshall, T.P. (2005). Photonics for the $21^{\text {st }}$ century. Consolidated Photonics European Initiative. Brussels: VDI - The Association of German Engineers.

Nosella, A. \& Petroni, G. (2007). Multiple network leadership as a strategic asset: The Carlo Gavazzi Space case. Long Range Planning, 40(2): 178-201.

NRC (National Research Council) (1998). Harnessing light - Optical science and engineering for the 21st century. Washington, D.C.: National Academy Press.

Orlikowski, W.J. (1992). The duality of technology: Rethinking the concept of technology in organizations. Organization Science, 3(3), 398-427.

Orton, J.D. \& Weick, K.E. (1990). Loosely coupled systems: A reconceptualization. Academy of Management Review, 15(2), 203-223. 
Osborn, R.N. \& Marion, R. (2009). Contextual leadership, transformational leadership and the performance of international innovation seeking alliances. Leadership Quarterly, 20(2), 191-206.

Osborn, R.N., Hunt, J.G. \& Jauch, L.R. (2002). Toward a contextual theory of leadership. Leadership Quarterly, 13, 797-873.

Pearce, C.L. \& Conger, J.A. (2003) (Eds.): Shared leadership. Reframing the hows and whys of leadership. Thousand Oaks: Sage.

Piore, M. \& Sabel, C. (1984). The second industrial divide. New York: Basic Books.

Poole, M.S. \& Van de Ven, A. (1989). Using Paradox to Build Management Theories. Academy of Management Review, 14(4), 562-578.

Porter, M.E. (1990). The competitive advantage of nations. New York: Free Press.

Porter, M.E. (1998). On competition. Boston, Mass.: Harvard Business School Press.

Pozzebon, M. (2004). The influence of a structurationist view on strategic management research. Journal of Management Studies, 41(2), 247-272.

Pred, A. (1990). Context and bodies in flux: Some comments on space and time in the writings of Anthony Giddens. In Clark, J., Modgil, C. \& Modgil, S. (Eds.): Anthony Giddens: Consensus and controversy (pp. 117-129). London: Falmer.

Rickman, A. (2000): Century of the photon - Brief article. Interview with Andrew Rickman president and CEO of Bookham Technology. In Electronic Times: http://findarticles.com/p/articles/mi_m0WVI/is_2000_August_7/ai_63989819/, (7th August 2000).

Romanelli, E. \& Khessia, O.M. (2005). Regional industrial identity: Cluster configurations and economic development. Organization Science, 16(4), 344-358. 
Rosenfeld, S.A. (1996). Overachievers: Business clusters that work. Prospects for regional development. Chapel Hill, NC: Regional Technology Strategy, Inc.

Saxanian, A.L. (1994). Regional advantage: Culture and competition in Silicon Valley and Route 128. Cambridge: Harvard University Press.

Selznick, P. (1957). Leadership in administration. New York: Harper \& Row.

Sjöstrand, S.-E., Sandberg, J. \& Tyrstrup, M. (2001) (Eds.). Invisible management. London: Thomson.

Sölvell, Ö., Linqvist, G. \& Ketels, C. (2003). The cluster initiative greenbook. Stockholm: Ivory Tower.

Suddaby, R. (2006). What grounded theory is not. Academy of Management Journal, 49, 633-642.

Sundaramurthy, C. \& Lewis, M. (2003). Control and collaboration: Paradoxes of governance. Academy of Management Journal, 28(3), 397-415.

Sydow, J., \& Lerch, F. (with Huxham, C. \& Hibbert, P.) (2007). Developing photonics clusters - Commonalities, Contrasts and Contradictions. Advanced Institute of Management (AIM) Research, London.

Sydow, J., Lerch, F. \& Staber, U. (2010). Planning for path dependence? The case of a network in the Berlin-Brandenburg optics cluster. Economic Geography, 86 (2), in print.

Sydow, J. \& Windeler, A. (1998). Organizing and evaluating interfirm networks - A structurationist perspective on network processes and effectiveness. Organization Science, 9(3), 265-284.

Uhl-Bien, M. (2006). Relational leadership theory: Exploring the social processes of leadership and organizing. Leadership Quarterly, 17, 654-676. 
Urry, J. (1991). Time and space in Giddens' social theory. In Bryant, C.G.A. \& Jarry, D. (Eds.), Giddens' theory of structuration: A critical appreciation (pp.160-175). London: Routledge.

Van Maanen, J. (1979). The fact of fiction in organizational ethnography. Administrative Science Quarterly, 24(4), 539-550.

Weeks, J. (2000). What do ethnographers believe? A reply to Jones. Human Relations, 53, 153-171.

Yammarino, F.J. \& Dansereau, F. (2008). Multi-level nature and multi-level approaches to leadership. Leadership Quarterly, 19, 135-141.

Yin, R.K. (2009). Case study research: Design and methods. $4^{\text {th }}$ edition. Thousand Oaks: Sage.

Yukl, G.A. (2006). Leadership in organizations. $6^{\text {th }}$ edition. Upper Saddle Rivers: Pearson Prentice-Hall.

Zucchella, A. (2006). Local cluster dynamics: Trajectories of mature industrial districts between decline and multiple embeddedness. Journal of Institutional Economics, 2(1), 2144. 
Table 1 Interviews in the four clusters

\begin{tabular}{|c|c|c|c|c|}
\hline Region & $\begin{array}{l}\text { Time } \\
\text { frame }\end{array}$ & $\begin{array}{l}\text { No. of } \\
\text { interviews }\end{array}$ & Organization & $\begin{array}{l}\text { Type of } \\
\text { organization }\end{array}$ \\
\hline $\begin{array}{l}\text { Berlin- } \\
\text { Branden- } \\
\text { burg }\end{array}$ & $2000-2006$ & $\begin{array}{l}1 \\
1 \\
1 \\
1 \\
2\end{array}$ & $\begin{array}{l}\text { Max-Born-Institute for Nonlinear Optics and Short } \\
\text { Pulse Spectroscopy } \\
\text { DLR (German Aerospace Center) } \\
\text { Optical Institute (Technical University Berlin) } \\
\text { MergeOptics GmbH } \\
\text { Clyxon Laser GmbH } \\
\text { OpTecBB e.V. }\end{array}$ & $\begin{array}{l}\text { RO } \\
\text { RO } \\
\text { RO } \\
\text { SME } \\
\text { SME } \\
\text { CR/NAO }\end{array}$ \\
\hline $\begin{array}{l}\text { Southern } \\
\text { Arizona }\end{array}$ & $\begin{array}{l}2004 / 2005 \\
\text { and } \\
2006 / 2007\end{array}$ & $\begin{array}{l}2 \\
1 \\
2 \\
2 \\
2\end{array}$ & $\begin{array}{l}\text { University of Arizona, Economic Development } \\
\text { Unit } \\
\text { Southern Arizona Technology Council } \\
\text { University of Arizona, Office of Economic and } \\
\text { Policy Analysis } \\
\text { University of Arizona, College of Optical Sciences } \\
\text { Large Binocular Telescope, Steward Observatory } \\
\text { Optical Electronics, Inc (OEI) } \\
\text { Raytheon Missile Systems } \\
\text { AOIA/Breault Research }\end{array}$ & $\begin{array}{l}\text { RDA } \\
\text { RDA } \\
\text { RO/RDA } \\
\text { RO } \\
\text { RO } \\
\text { SME } \\
\text { LC } \\
\text { CR/SME }\end{array}$ \\
\hline Scotland & $2005 / 2006$ & $\begin{array}{l}2 \\
1 \\
1 \\
1 \\
2 \\
1 \\
1 \\
2\end{array}$ & $\begin{array}{l}\text { Institute of Photonics, University of Strathclyde } \\
\text { UK Astronomy Technology Centre (Royal } \\
\text { Observatory Edinburgh) } \\
\text { Scottish Enterprise } \\
\text { Photonix Limited } \\
\text { Intense } \\
\text { Forth Dimension Displays Limited } \\
\text { Optimat Limited } \\
\text { Thales Optronics } \\
\text { SELEX Sensors and Airborne Systems } \\
\text { SOA }\end{array}$ & $\begin{array}{l}\text { RO } \\
\text { RO } \\
\text { RDA } \\
\text { RO/SME } \\
\text { SME } \\
\text { SME } \\
\text { E } \\
\text { LC } \\
\text { LC } \\
\text { CR/SME }\end{array}$ \\
\hline $\begin{array}{l}\text { West } \\
\text { Midlands }\end{array}$ & 2006 & $\begin{array}{l}1 \\
1 \\
2\end{array}$ & $\begin{array}{l}\text { Photonics Research Group at Aston University, } \\
\text { Birmingham } \\
\text { Laser Optical Engineering Ltd } \\
\text { Bookham Technology plc } \\
\text { Photonics Cluster (UK) }\end{array}$ & $\begin{array}{l}\text { RO } \\
\text { SME } \\
\text { LC } \\
\text { CR/NAO }\end{array}$ \\
\hline
\end{tabular}

$\mathrm{RO}=$ research organization; $\mathrm{SME}=$ small and medium- seized enterprises; $\mathrm{LC}=$ large company; $\mathrm{RDA}=$ regional development agency; $\mathrm{E}=$ external expert; $\mathrm{CR}=$ cluster representative; $\mathrm{NAO}=$ network administrative organization 
Table 2 Characteristics of the four clusters

\begin{tabular}{|c|c|c|c|c|}
\hline $\begin{array}{l}\text { Dimension } \\
\text { (1) Properties }\end{array}$ & $\begin{array}{l}\text { Berlin- } \\
\text { Brandenburg }\end{array}$ & $\begin{array}{l}\text { Southern } \\
\text { Arizona }\end{array}$ & Scotland & West Midlands \\
\hline Geographic scale & concentrated & concentrated & dispersed & dispersed \\
\hline $\begin{array}{l}\text { Economic size } \\
\text { (firms/employees)* }\end{array}$ & $260 / 7,400$ & $250 / 25,000$ & $90 / 4,000$ & $60 /$ n.a. ${ }^{* *}$ \\
\hline Main domain & science & industry & science & industry \\
\hline Value chain & incomplete & incomplete & incomplete & incomplete \\
\hline Level of interaction & high & $\begin{array}{l}\text { high, but } \\
\text { centralized }\end{array}$ & high & low \\
\hline $\begin{array}{l}\text { Involvement in cluster } \\
\text { leadership }\end{array}$ & relatively high & low & low & low \\
\hline \multicolumn{5}{|l|}{ (2) ‘Cluster Rules’ } \\
\hline Collective identity & pronounced & present & present & not present \\
\hline Perceived legitimacy & high & high & high & low \\
\hline \multicolumn{5}{|l|}{ (3) 'Cluster Resources’ } \\
\hline Financial resources & significant & hardly any & some & significant \\
\hline \multicolumn{5}{|l|}{ (4) Phase of development } \\
\hline $\begin{array}{l}\text { Cluster organization age } \\
\text { in years in } 2006\end{array}$ & 5 & 15 & 15 & 5 \\
\hline Phase & developing & developing & developing & emerging \\
\hline
\end{tabular}

* The numbers refer to different years. $* *$ n.a. $=$ not available

${ }^{1}$ Though the notion of relational leadership has been used before for signifying either a particular facilitative style of leadership (Murrell, 1997) or as an alternative theory of leadership which is grounded in a constructivist perspective and emphasizes the importance of social contexts in general and of the embeddedness of leadership processes in ongoing relationships in particular (e.g. Uhl-Bien, 2006), we draw on it simply to highlight the relation-based character of leading (in) clusters and the necessarily relation-focused mobilization of action. In contrast to others, we do not restrict the notion to the leaderfollower dyad but rather wish to emphasize the sets of relationships actors, including leaders and followers, are embedded in.

${ }^{2}$ Specific networks in those clusters were also recognized but were - like leadership in clusters - not the primary focus of this study.

${ }^{3}$ While there are certainly also informal or invisible leadership arenas (Sjöstrand et al., 2001) in clusters, these were not considered in this study.

${ }^{4}$ For more information on road mapping in the process of reflexive network/cluster structuration see Sydow, Lerch and Staber (2010). 
5 'The 'absence' of leadership in the face of only minimalistic influencing has even been stated for some organizations, in this case a knowledge-intensive R\&D company (Alvesson \& Sveningsson, 2003).

${ }^{6} \mathrm{We}$ are grateful to a LQ reviewer for pointing this limitation out to us. 